\title{
Morfologia externa dos estágios imaturos de heliconíneos neotropicais: I. Eueides isabella dianasa (Hübner, 1806) ${ }^{1}$
}

\author{
Fabiano F. Antunes ${ }^{2}$ \\ Ayres de O. Menezes Jr. ${ }^{3}$ \\ Maurício Tavares ${ }^{4}$ \\ Gilson R.P. Moreira ${ }^{4}$
}

\begin{abstract}
External morphology of the immature stages of neotropical heliconians: I. Eueides isabella dianasa (Hübner, 1806). The external features of egg, larva and pupa of Eueides isabella dianasa (Hübner, 1806) (Lepidoptera, Nymphalidae, Heliconiinae) are described and illustrated, based upon light and scanning electron microscopy.
\end{abstract}

KEYwords. Heliconiinae; immature stages; Lepidoptera; morphology; Nymphalidae.

\section{INTRODUÇÃO}

As borboletas do maracujá (Lepidoptera, Nymphalidae, Heliconiini) têm sido amplamente estudadas no que concerne à biologia e ecologia evolutiva (Benson et al. 1976; Brown 1981; GILBERT 1991). A taxonomia proposta para o grupo tem como base preponderantemente os caracteres morfológicos dos adultos (e. g., Emsley 1963; Brown \& Mielke 1972; Holzinger \& Holzinger 1994). Poucos esforços foram dispendidos quanto à caracterização dos estágios imaturos, os quais são ainda desconhecidos ou parcialmente descritos para algumas espécies. Estudos comparativos neste contexto restringem-se à fauna de Trinidad (Fleming 1960; Beebe et al. 1960). No que concerne especificamente à ultraestrutura do tegumento, informações são inexistentes para os estágios imaturos da grande maioria das espécies de heliconíneos. $\mathrm{O}$ conhecimento detalhado a este respeito, principalmente da amplitude de variação intraespecífica, é fator importante para o estabelecimento de suas relações filogenéticas e biogeográficas, bem como em estudos futuros sobre mimetismo no estágio larval, ainda pouco explorado dentro dos heliconíneos (BRown 1981; LeE et al. 1992; BROWER 1997). Com a publicação de uma série de artigos com este objetivo, iniciada com o presente trabalho, pretende-se preencher tal lacuna.

De acordo com Holzinger \& Holzinger (1994), são reconhecidas doze subespécies de Eueides isabella (Cramer, 1782), uma espécie amplamente distribuída na Região Neotropical. Eueides isabella dianasa (Hübner, 1806), segundo os mesmos autores, apresenta a distribuição mais austral, ocorrendo no Brasil, desde Santa Catarina à Bahia e Pará. Temos também registros desta subespécie para Porto Alegre, Rio Grande do Sul (G.R.P. Moreira, dados inéditos). Em adição, BiEZANKO et al. (1978) citam a ocorrência de E. isabella dianasa no Uruguai.

Os adultos de E. isabella dianasa são freqüentemente coletados em bordas de mata e em habitats perturbados (BROwN \& MiLKE 1972; Brown 1992). Os ovos são depositados sob as folhas maduras de diversas espécies de Passiflora Linnaeus (Passifloraceae), pertencentes aos subgêneros Distephana e Granadilla (Benson et al. 1976; Brown 1981). As larvas de E. isabella dianasa são comumente encontradas sobre Passiflora edulis, P. alata e P. odontophyla (BRown \& MilKe 1972; OtERo 1986). Na Colômbia, $E$. isabella é citada como potencialmente danosa ao cultivo de P. edulis f. flavicarpa (CHACON \& RoJAs

1. Contribuição $n^{\circ} 377$ do Departamento de Zoologia, Universidade Federal do Rio Grande do Sul.

2. Curso de Pós-Graduação em Biologia Animal, Departamento de Zoologia , Instituto de Biociências, UFRGS. Av. Bento Gonçalves 9500, 91501-970 Porto Alegre-RS, Brasil.

3. Departamento de Agronomia, Universidade Estadual de Londrina. Caixa Postal 6001, 86051-970 Londrina-PR, Brasil.

4. Departamento de Zoologia , Instituto de Biociências, UFRGS. Av. Bento Gonçalves, 9500, 91501-970 Porto Alegre-RS, Brasil. Endereço eletrônico: gilson.moreira@ufrgs.br 
1984). No Brasil, segundo Brown (1992), também torna-se praga de $P$. edulis em certas ocasiões.

As principais características relativas à morfologia genérica dos estágios imaturos de $E$. isabella foram descritas e ilustradas por BEEBE et al. (1960) e a quetotaxia da larva de primeiro ínstar, por Fleming (1960). Tais estudos tiveram como base material hoje considerado E. isabella isabella (Holzinger \& Holzinger 1994). No presente trabalho, revisam-se os caracteres apresentados por esses autores e, com base na microscopia óptica e eletrônica de varredura, acrescentam-se dados sobre: 1) ultraestrutura do ovo;2) quetotaxia primária e secundária da larva; 3) identificação morfométrica dos ínstares; 4) morfologia genérica e ultraestrutural da pupa.

\section{MATERIAL E MÉTODOS}

Os espécimes utilizados foram coletados nos municípios de Ilhota, Santa Catarina e de Maquiné, Rio Grande do Sul, sobre cultivos de Passiflora edulis Sims. Parte do material foi fixado em fluído de Dietrich e preservado em etanol $70 \%$. Alguns exemplares foram mantidos em laboratório sobre ramos de $P$. edulis, que foram dispostos em garrafas plásticas contendo água e cobertos por tela de malha fina. Exceto quando mencionado, as análises microscópicas e ilustrações correspondentes foram efetuadas com base na comparação de, pelo menos, cinco exemplares.

As observações relativas à morfologia genérica foram realizadas com o material preservado, utilizando-se um estereomicroscópio Leika $\mathrm{MZ12}^{\circledR}$, equipado com iluminação por fibra óptica. Especificamente para as cápsulas cefálicas, o material foi reidratado, clarificado em KOH $10 \%$ e montado sob lâmina/lamínula, utilizando-se gelatina glicerinada como meio de inclusão. As ilustrações correspondentes foram efetivadas com o auxílio de uma grade micrométrica acoplada à ocular de uma lupa Spencer ${ }^{\circledR}$. O padrão de coloração da larva de quinto ínstar e da pupa foi representado em aquarela, tendo como base a observação de espécimes vivos sob o estereomicroscópio. Os exemplares usados na microscopia eletrônica foram primeiramente reidratados, imersos em nitrogênio líquido, liofilizados e montados com fita de dupla face sobre suporte metálico. A seguir, foram cobertos com ouro em um metalizador Balzers Union ${ }^{\circledR} \mathrm{e}$ observados em um aparelho JEOL $5800^{\circledR}$.

A nomenclatura referente à quetotaxia da larva de primeiro ínstar baseou-se em Fleming (1960), com modificações propostas por SteHR (1987). Este último foi também utilizado para a descrição do padrão dos ganchos dos larvópodos. Com relação à descrição dos escolos adotou-se aquela utilizada por BEEBE et al. (1960). Na caracterização da pupa seguiu-se MOSHER (1916), com exceção dos tubérculos dorsais e laterais, para os quais também adotou-se BEEBE et al. (1960).

As medidas da cápsula cefálica utilizadas na análise morfométrica foram tomadas com o auxílio de uma ocular micrométrica acoplada ao microscópio estereoscópico, tendo como base exemplares intactos preservados. As medidas da cápsula cefálica referem-se à sua maior largura, em vista frontal.

\section{RESULTADOS E DISCUSSÃO}

\section{Ovo}

Apresenta-se em forma de cúpula, com face dorsal achatada e base alargada (Fig. 1). As dimensões (média \pm erro padrão) correspondentes à altura e diâmetro da base, obtidas para 10 exemplares, foram de $0,76 \pm 0,01$ e de $0,82 \pm 0,01 \mathrm{~mm}$, respectivamente. Tais valores encontram-se abaixo daqueles apontados por BEEBE et al. (1960), consistindo provavelmente em variação ao nível subespecífico. Conforme relatado por BEEBE et al. (1960) e Brown (1981), possui cor creme, com tonalidades variando desde o verde ao amarelo pálido, dependendo do estágio de desenvolvimento embrionário considerado.

À semelhança dos demais heliconíneos, apresenta carenas horizontais (Figs. 1, 2; Hr) e verticais (Figs. 1, 2; Vr), que variaram na população estudada em número de 8 a 9 e de 17 a 19 , respectivamente. Tais valores se aproximam daqueles apontados para E. isabella isabella por BEEBE et al. (1960). Na metade inferior, as carenas encontram-se ordenadas retilineamente, delimitando células de formato retangular (Fig. $1 ; \mathrm{Lc}$ ), com ângulos internos de formato arrendondado. $\mathrm{Na}$ metade superior, não apresentam tal orientação, delimitando células em forma de pentágono ou hexágono (Fig. 1; Uc), com borda interna de formato circular. As carenas destas últimas apresentam longitudinalmente uma crista fina (Fig. 3; Mc), situada em posição mediana.

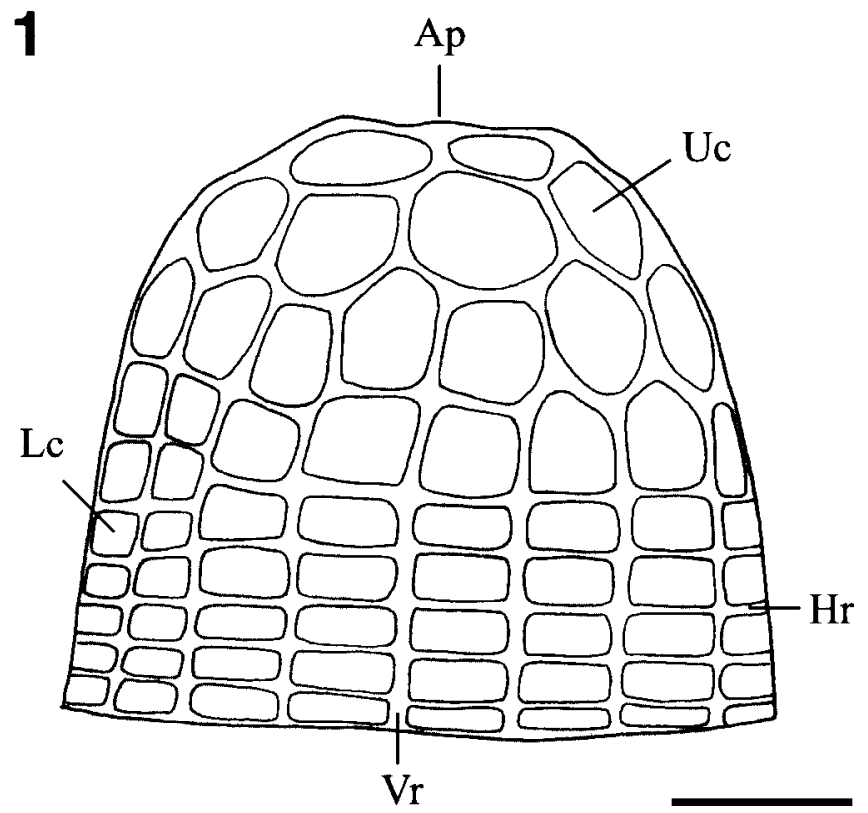

Fig. 1. Ovo de E. isabella dianasa em vista lateral. Ap= pólo anterior; $\mathrm{Hr}=$ carena horizontal; $\mathrm{Lc}=$ célula inferior; $\mathrm{Uc}=$ célula superior; $\mathrm{Vr}=$ carena vertical. Barra $=0,25 \mu \mathrm{m}$. 
A área micropilar situa-se no pólo anterior do ovo de $E$. isabella dianasa, seguindo o padrão conhecido para os lepidópteros. À semelhança do verificado para os demais Papilionoidea, é depositado de maneira que o eixo micropilar (linha imaginária entre os pólos anterior e posterior) situa-se em posição perpendicular ao substrato (HINTON 1981). Em consequência, após a oviposição, os pólos anterior e posterior assumem as posições superior e inferior, respectivamente. A área micropilar (Fig. 4) situa-se em uma célula em forma de pentágono, a qual confere o aspecto achatado ao ovo dorsalmente (Fig. 1; Ap). A superfície desta apresenta ornamentação diferenciada das demais células, nas quais é lisa. Ou seja, o cório possui diversas células menores que tendem ao formato arredondado na porção externa e triangular na interna, as quais convergem para a área central, onde se localizam as micrópilas (Fig. 4; Mp). Tais regiões da área micropilar foram denominadas por Downey \& Allyn (1981), respectivamente, de ânulo e roseta.

Em cada vértice das carenas das células superiores, situase uma aerópila circular (Figs. 3, 5; Ac), com peritrema pouco pronunciado. Outro tipo de aerópila (Fig. 6), com peritrema evidentemente delineado e de formato oval, dividido medianamente, foi observado em pequeno número na superfície das células superiores. Nossas observações sugerem a existência de uma câmara de ar localizada internamente no cório, conectada ao meio externo pelos orifícios descritos, o que deve ser melhor investigado. A existência de aerópilas, semelhantes em forma e posição às de E. isabella dianasa, tem sido descrita para o estágio de ovo de outros lepidópteros, incluindo ninfalídeos (Hinton 1981).

\section{Larvas}

No primeiro ínstar de E. isabella dianasa, a morfologia genérica da cápsula cefálica (Fig. 7), bem como sua ultraestrutura e das peças bucais (Figs. 10, 11, 12, 13, 14) segue o descrito por STEHR (1987). As antenas (Fig. 12) encontram-se inseridas em uma área membranosa eversível lisa, assim como em Heliconius erato phyllis (Fabricius, 1775) (KAMINSKi et al., no prelo).

A quetotaxia da cápsula cefálica (Fig. 7) aproxima-se daquela descrita preliminarmente por FLEMING (1960). As maiores cerdas da cápsula cefálica pertencem ao grupo póstero-dorsal ( $\mathrm{P} 1$ e $\mathrm{P} 2$ ), estas diferindo pouco entre si quanto ao comprimento. A cerda $\mathrm{P} 2$ situa-se dorsalmente em relação à $\mathrm{P} 1$, a qual localizase próxima à área adfrontal. As duas cerdas adfrontais (AF1 e AF2) situam-se externamente à área adfrontal e possuem
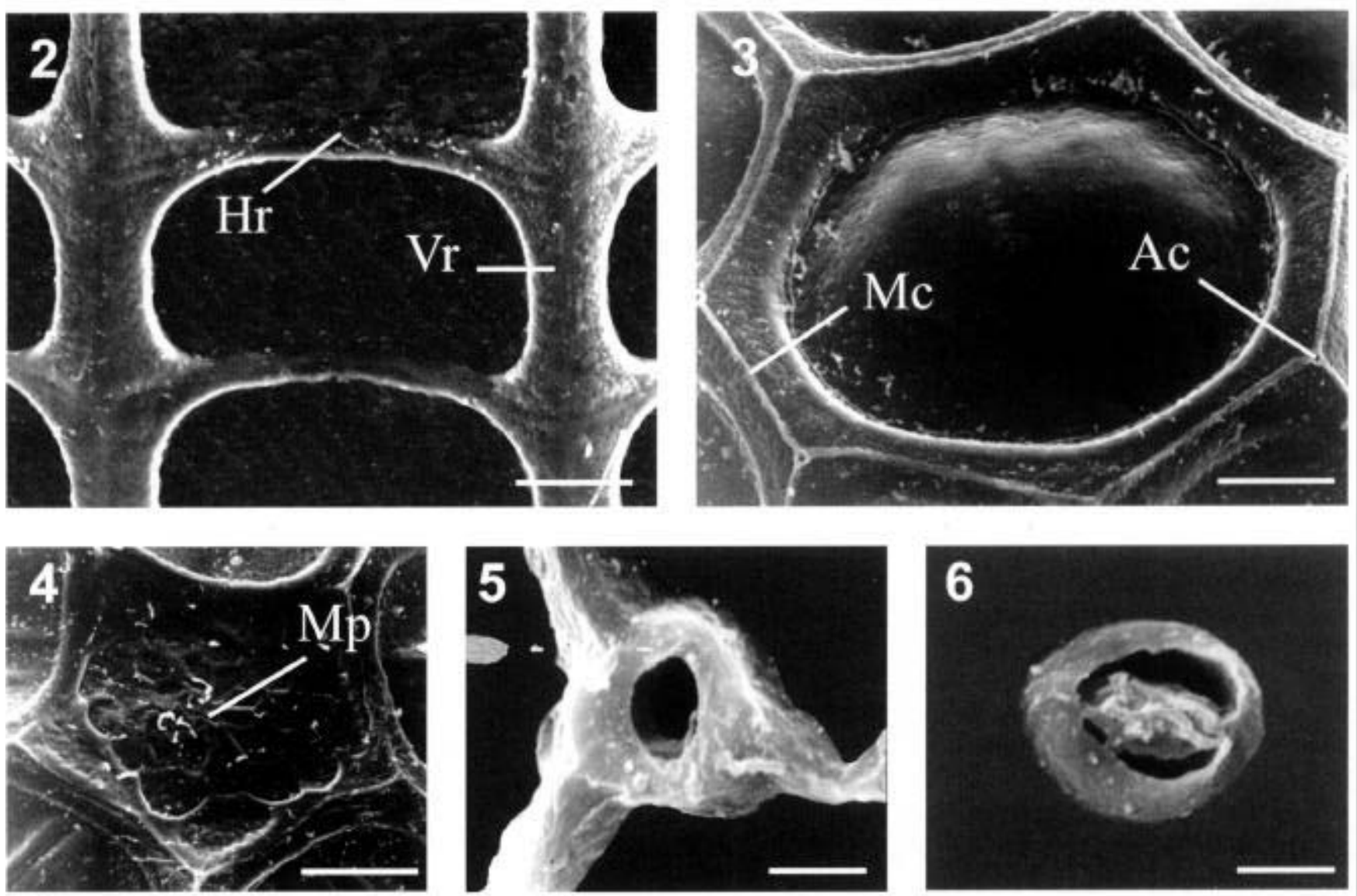

Figs. 2-6. Ovo de E. isabella dianasa em microscopia eletrônica de varredura. 2, células inferiores; 3, célula superior; 4, região micropilar; $\mathbf{5}$, aerópila circular; 6, aerópila oval. $\mathrm{Ac}=$ aerópila; $\mathrm{Hr}=$ carena horizontal; $\mathrm{Mc}=$ crista mediana; $\mathrm{Mp}=$ micrópilas; $\mathrm{Vr}=$ carena vertical. $\mathrm{Barras}=50,50,50,2 \mathrm{e}$ $2 \mu \mathrm{m}$, respectivamente. 
comprimentos equivalentes. As cerdas anteriores (A1, A2 e A3), a cerda lateral (L1), a cerda frontal (F1) e as cerdas clipeais (C1 e C2) estão presentes, seguindo o padrão descrito para Lepidoptera (STEHR 1987). Quanto à posição, difere apenas a cerda A3, a qual encontra-se deslocada dorsalmente, distanciando-se dos estemas.

O grupo estematal está representado por três cerdas $(\mathrm{S} 1$, $\mathrm{S} 2$ e S3). A cerda S1 encontra-se dentro do semi-círculo formado pelos estemas, localizada próximo aos estemas 3 e 4 . A S2 situase junto à abertura do semi-círculo, próxima ao estema 1. A S3 é a mais posterior deste grupo, situada pouco acima da linha do estema 6 , sendo sua inserção visível somente em vista lateral. Ventralmente, na área genal, encontra-se o grupo sub-estematal consistindo de três cerdas: SS1, SS2 e SS3. A SS1 é a mais ventral, localizando-se próxima à base da mandíbula. É uma cerda pouco esclerotinizada, não aparente em vista frontal. A SS2 é conspícua, em vista lateral, e situa-se posteriormente ao estema 5 , entre este e o 6 . A SS3 origina-se próxima à base da antena, entre esta e o estema 5. Algumas cerdas da região ventral, associadas às peças bucais, não foram representadas por não serem comumente nomeadas (MILLER \& OTERO 1994).

FLEMING (1960) relata a presença de somente um par de poros frontais (Fig. 7; Fa) localizados medianamente na fronte. No presente estudo, além deste par de poros foram constatados os seguintes: MDa, Pb, Pa, Aa, Sb e $\mathrm{Sa}$ (Fig. 7). O poro MDa está localizado no vértice da cabeça, posteriormente à cerda $\mathrm{P} 2$. $\mathrm{O}$ par $\mathrm{Pb}$ está localizado frontalmente às cerdas $\mathrm{P}$ 2. $\mathrm{O}$ par $\mathrm{Pa}$ é ventral em relação ao $\mathrm{Pb}$, localizando-se entre as cerdas $\mathrm{A} 2 \mathrm{e}$ A1. O par Aa está localizado lateralmente à cerda $\mathrm{A} 2$, próximo ao estema 2. O par Sb encontra-se ao lado do estema 4. O par Sa é visualizado, em vista lateral, entre o estema 6 e a cerda S3.

$\mathrm{Na}$ placa protorácica, estão presentes, de cada lado, as cerdas anteriores (Figs. 8, 15) XD2, D1 e D2, sendo D1 medianadorsal e mais longa. A cerda D2 localiza-se posteriormente na mesma placa. As cerdas D1 e D2 estão presentes em todos os demais segmentos do tórax e do abdômen, sendo D1 sempre localizada dorsalmente e mais longa. A inexistência da cerda XD1 no protórax e o tamanho relativo das cerdas D1 e D2 diferem do padrão de Lepidoptera apresentado porSTEHR (1987). FLEMING (1960) não constatou a presença de poros na placa protorácica de E. isabella, observando apenas um par de poros em Dryas iulia (Fabricius, 1775), denominado XDc. No presente estudo, observou-se dois pares de poros em E. isabella, um deles correspondendo à XDc, por localizar-se anteriormente à $\mathrm{D} 2$ e entre $\mathrm{D} 1$ e XD2, sendo mais próximo desta. O segundo poro, aqui denominado $\mathrm{XDb}$, encontra-se lateralmente à $\mathrm{XD} 2$, próximo à margem da placa.

O grupo de cerdas subdorsais está representado por SD1 e SD2 nos três segmentos torácicos, sendo SD1 superior e anterior à SD2. Nos segmentos abdominais apenas SD1 está presente, contrastando com o padrão já mencionado (STEHR 1987).

O grupo lateral está representado por L1 e L2 no protórax, ambas anteriores ao espiráculo e localizadas sobre a mesma pinácula. No meso e metatórax somente as cerdas L1 estão presentes, localizadas acima da linha dorso-pleural. Do primeiro ao oitavo segmentos abdominais estão presentes as setas L1 e L2, sendo L1 mais longa e localizada posteriormente e um pouco abaixo dos espiráculos. A L2 encontra-se afastada ventralmente aos espiráculos e à cerda L1. No nono segmento, encontra-se apenas a cerda $L 1$, representada por uma cerda pequena e fina.

O grupo subventral está representado por duas cerdas (SV1 e SV2) sobre a mesma pinácula no protórax. No meso e metatórax, bem como no primeiro segmento abdominal, apenas a cerda SV1 está presente. Do segundo ao sexto segmento abdominal, encontramos as cerdas SV1 e SV2, enquanto do sétimo ao décimo, observa-se a ocorrência de SV1 somente. No décimo segmento, observa-se a presença de uma cerda paraproctal (PP), localizada acima da abertura anal e direcionada posteriormente (STEHR 1987).

Os espiráculos localizam-se no primeiro segmento torácico, e do primeiro ao oitavo abdominais, mantendo este padrão em todos os ínstares. $\mathrm{Na}$ larva de primeiro ínstar, o peritrema apresenta-se circular.

No segundo ínstar, ocorrem grandes modificações na quetotaxia, com o aparecimento dos escolos. Estes apresentam ramificações e ápice afilados quebradiços (Figs. 17 e 18), diferindo do primeiro ínstar onde as cerdas são do tipo calaza (Fig. 16), com cerda terminal lisa. O protórax é o segmento mais conservado em relação às cerdas primárias, supostamente por não sofrer a adição de escolos. Assim, pode-se distinguir as cerdas da placa protorácica (XD2, D1 e D2), que apresentam-se reduzidas, sendo D2 a mais curta. As demais cerdas não apresentam modificações significativas, com exceção da adição de uma subventral (SV3), mais curta e fina, localizada posteriormente a este grupo.

No meso e metatórax aparecem dois pares de escolos, um supraespiracular e o outro dorsal, antecipando a localização que se mantém até o quinto ínstar (Fig. 9). Nestes dois segmentos, permanecem uma cerda subdorsal, uma cerda lateral e ocorre a adição de uma subventral àquela existente no primeiro ínstar.

Nos segmentos abdominais, surgem três pares de escolos (Fig. 9), um par dorsal (So), um par supraespiracular (Sp) e um par subespiracular $(\mathrm{Sl})$. O nono segmento abdominal segue o mesmo padrão do primeiro ínstar quanto à quetotaxia, permanecendo assim até o quinto ínstar. No décimo segmento abdominal (Fig. 9), temos a adição de um par de escolos anal (Sn) e o desaparecimento de SV1. Na porção mais terminal temos quatro pares de cerdas, como no primeiro ínstar: D1, D2, SD1 e PP, além da adição de um par de cerdas, situadas ventrolateralmente, cuja homologia não foi determinada.

No terceiro ínstar, podem ser notadas diferenças, principalmente em relação às cerdas do protórax. As cerdas XD2 e D1 já não compartilham a mesma placa esclerotinizada, tendo cada uma sua própria pinácula. A D2 não apresenta placa esclerotinizada basal. Os demais segmentos, tanto torácicos quanto abdominais, seguem o padrão descrito para o segundo ínstar.

$\mathrm{O}$ quarto ínstar difere quanto à quetotaxia do décimo 

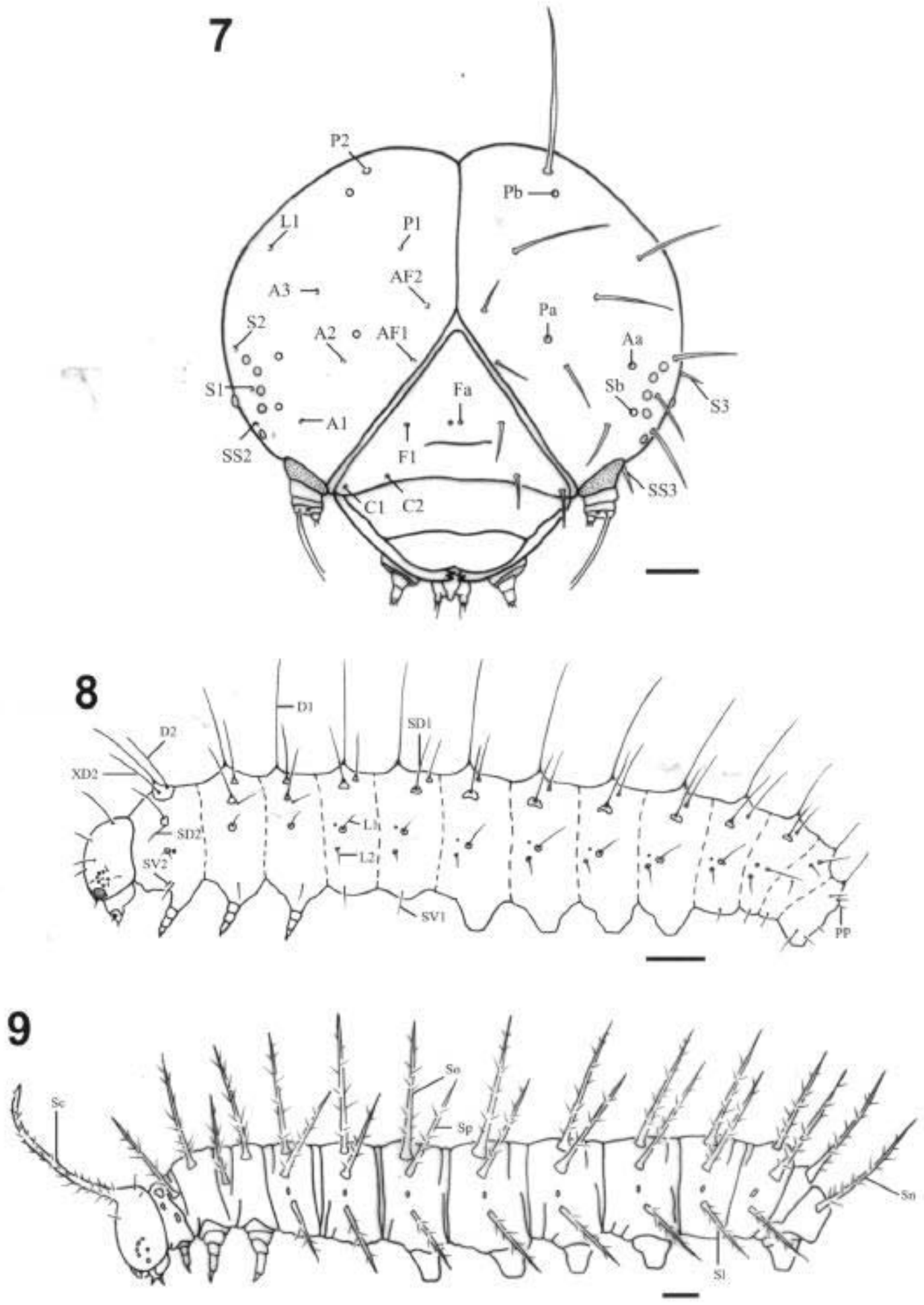

Figs. 7-9. Larva de E. isabella dianasa. 7, cápsula cefálica de larva de primeiro ínstar, em vista frontal; 8, larva de primeiro ínstar, em vista lateral; 9, larva de quinto ínstar, em vista lateral. $\mathrm{A}=$ cerda anterior; $\mathrm{Aa}=$ poro anterior; $\mathrm{AF}=$ cerda adfrontal; $\mathrm{C}=$ cerda clipeal; $\mathrm{D}=\mathrm{cerda}$ dorsal; $\mathrm{F}=$ cerda frontal; $\mathrm{Fa}=$ poro frontal; $\mathrm{L}=$ cerda lateral; $\mathrm{P}=$ cerda póstero-dorsal; $\mathrm{Pa}$ e $\mathrm{Pb}=$ poros póstero-dorsais; $\mathrm{S}=$ cerda estematal; $\mathrm{Sb}=$ poro estematal; $\mathrm{Sc}=$ escolo cefálico; $\mathrm{SD}=$ cerda supra-dorsal; $\mathrm{Sl}=$ escolo sublateral; $\mathrm{Sn}=$ escolo anal; $\mathrm{So}=$ escolo dorsal; $\mathrm{Sp}=$ escolo supralateral; $\mathrm{SS}=$ cerda subestematal; $\mathrm{SV}=$ seta subventral. Barras $=0,1 ; 0,25$ e $1 \mathrm{~mm}$; respectivamente. 

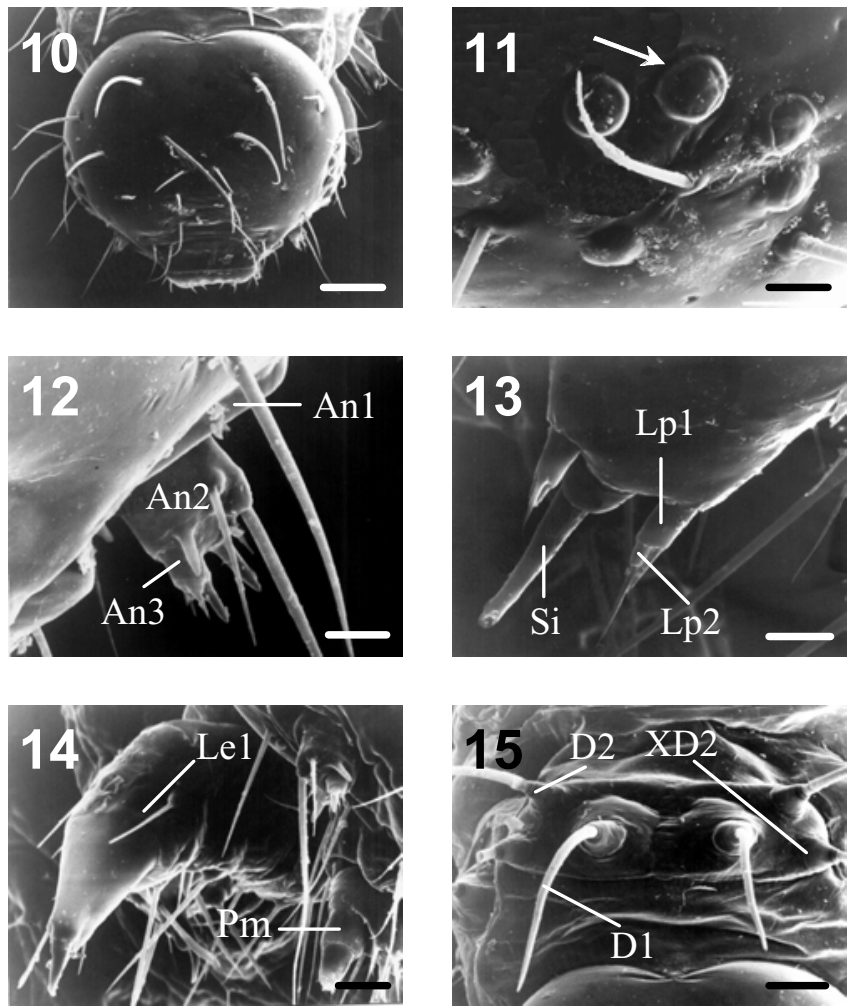

Figs. 10-15. Larva de primeiro ínstar de E. isabella dianasa em microscopia eletrônica de varredura. 10, vista frontal da cápsula cefálica; 11, vista lateral dos estemas (seta); 12, antena em vista frontal; 13, espinarete e palpos labiais em vista látero-ventral; 14, vista láteroventral da região anterior da larva; 15, vista dorsal do primeiro segmento torácico. $\mathrm{An}=$ segmento da antena; $\mathrm{D}=$ cerda dorsal; Le $1=$ perna protorácica; $\mathrm{Lp}=$ segmento do palpo labial; $\mathrm{Pm}=$ palpo maxilar; $\mathrm{Si}=$ espinarete; Barras $=100,20,20,10,20$ e $100 \mu \mathrm{m}$, respectivamente.

segmento abdominal. Além dos quatro pares de cerdas e do par de escolos anal, tem-se a adição de uma fileira ventral de cerdas.

No quinto ínstar, os espiráculos têm forma elíptica, sendo o diâmetro daquele do oitavo segmento abdominal distintamente maior. O aparato filtrador apresenta-se formado por lamelas transversais ao maior diâmetro, cobertas por densa pilosidade (Fig. 19). Os ganchos são unisseriais e triordinais, diferindo do primeiro ínstar, onde são unisseriais e uniordinais.

Conforme BeEBe et al. (1960), E. isabella, juntamente com Eueides aliphera (Godart, 1819), é uma das espécies mais variáveis em termos de coloração. A cabeça é preta com manchas brancas (Fig. 20). Ao longo do corpo notam-se três faixas longitudinais. A primeira é dorsal e apresenta coloração preta com bandas brancas transversais, com exceção do oitavo e nono segmentos abdominais onde apresenta-se alaranjada e do décimo segmento onde varia de amarela a branca. A segunda faixa é lateral e possui coloração amarela. A terceira faixa é verde translúcida e dela fazem parte as pernas torácicas e os larvópodos. Os escolos variam de acinzentados a pretos. À medida que a larva atinge seu maior desenvolvimento, as áreas dorsais pretas adquirem a cor vermelho-vinho, tornando-se totalmente alaranjada ao final do quinto ínstar.
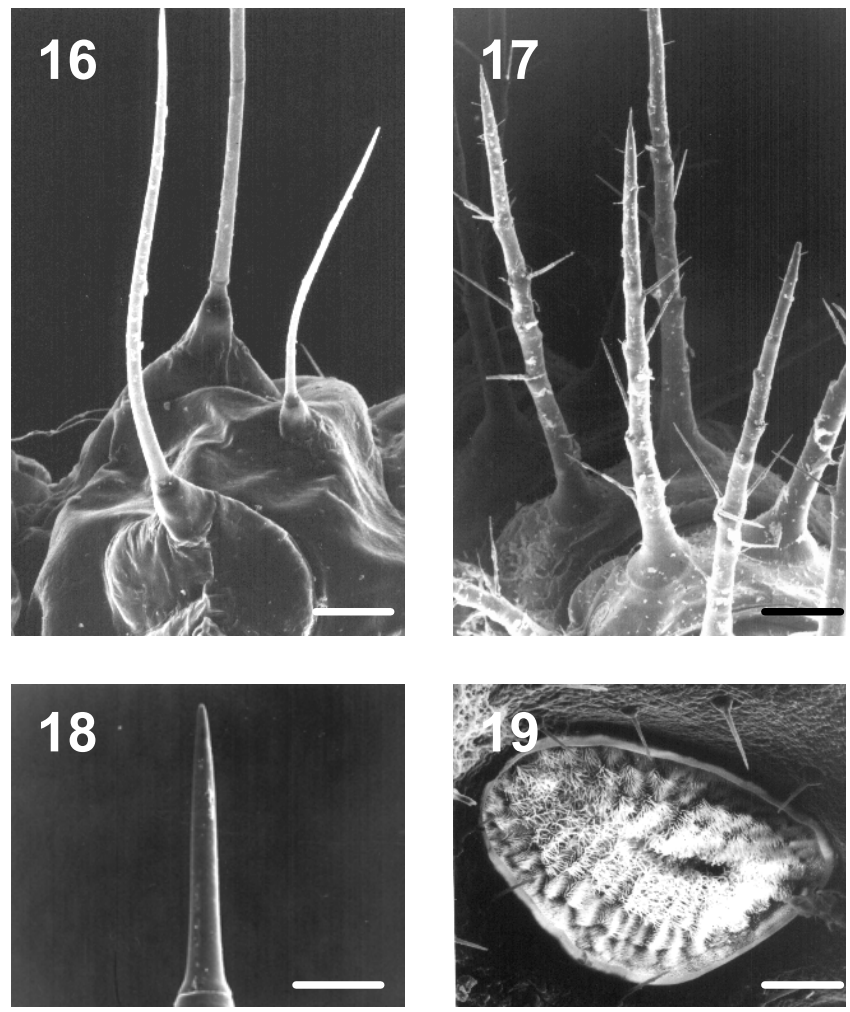

Figs. 16-19. Larva de E. isabella dianasa em microscopia eletrônica de varredura. 16, cerdas primárias do tipo calaza em vista lateral; 17, escolos da larva de quinto ínstar em vista lateral; 18, porção terminal de um escolo da larva de quinto ínstar; 19, espiráculo do oitavo segmento abdominal da larva de quinto ínstar, em vista lateral. Barras $=50,500,50$ e $50 \mu \mathrm{m}$.

\section{Identificação dos ínstares larvais}

As medidas de tendência central e dispersão e as razões de crescimento da largura da cápsula cefálica dentre os ínstares, para as lagartas coletadas, estão apresentadas na Tabela I. Obteve-se a seguinte equação de crescimento: $\ln \mathrm{y}=-1,264+$ $0,432 \mathrm{x}, \mathrm{n}=96, \mathrm{r}^{2}=0,987, \mathrm{p}<0,001$. As medidas de dispersão demonstram que não há sobreposição da largura da cápsula cefálica dentre os ínstares, o que permite a identificação direta destes. A baixa variabilidade dentre as razões de crescimento

Tabela I. Média aritmética e erro padrão (EP), intervalo de variação $(\mathrm{InV})$ e razão de crescimento ( $\mathrm{RaC})$ da largura da cápsula cefálica dentre os ínstars de E. isabella dianasa.

\begin{tabular}{|c|c|c|c|c|}
\hline \multirow[b]{2}{*}{ Ínstar } & \multirow[b]{2}{*}{ Lagartas (n) } & \multicolumn{3}{|c|}{ Largura da cápsula cefálica (mm) } \\
\hline & & Média \pm EP & $\operatorname{InV}$ & $\mathrm{RaC}$ \\
\hline I & 21 & $0,456 \pm 0,008$ & $0,336-0,522$ & - \\
\hline II & 15 & $0,624 \pm 0,006$ & $0,594-0,684$ & 1,36 \\
\hline III & 24 & $0,993 \pm 0,011$ & $0,888-1,111$ & 1,59 \\
\hline IV & 23 & $1,602 \pm 0,140$ & $1,480-1,702$ & 1,61 \\
\hline $\mathrm{V}$ & 13 & $2,556 \pm 0,035$ & $2,392-2,808$ & 1,59 \\
\hline
\end{tabular}



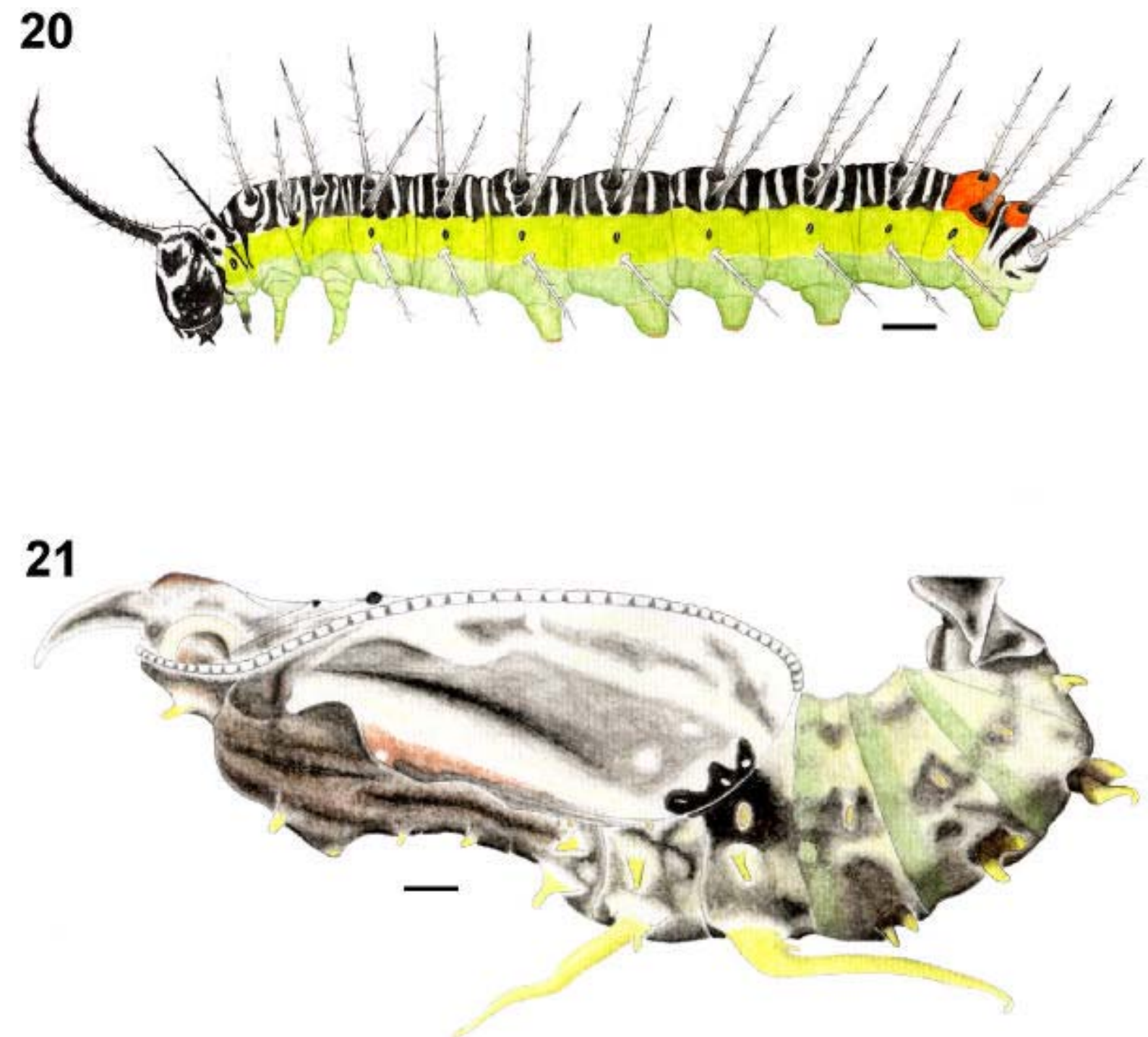

Figs. 20-21. Padrão de coloração de E. isabella dianasa. 20, larva de quinto ínstar; 21, pupa. Barras $=1 \mathrm{~mm}$.

entre os ínstares, associada ao elevado grau de ajuste dos dados à equação exponencial estimada, demonstram que a cápsula cefálica cresce segundo uma progressão geométrica dentre os ínstares. A razão de crescimento média de 1,53 encontrada aproxima-se daquela obtida para a maioria dos lepidópteros, seguindo, dessa forma, a regra de Brooks-Dyar (Daly 1985).

\section{Pupa}

De acordo com a caracterização geral de Nymphalidae (Mosher 1916), a pupa não possui sutura epicranial e tem as pernas pro- e mesotorácicas estendendo-se anteroventralmente até a região ocular (Fig. 22).

Os olhos (Fig. 28) possuem duas regiões distintas, compostas por uma estreita banda de aspecto lustroso (Gr) que circunda uma porção esculturada central (Sr), conforme encontrado nos demais lepidópteros (MosHer 1916). Da mesma maneira, o clípeo (Figs. 22 e 24, Cl) situa-se em posição mediana, delimitado lateralmente por suturas que partem das invaginações dos braços anteriores do tentório. A seguir, situase o labro, que encontra-se limitado lateralmente pelas mandíbulas, não funcionais (Fig. 22; Md).

As antenas (Fig. 22; An) originam-se na região dorsomediana da cabeça e acompanham ventralmente as margens externas da asa mesotorácica, apresentando a porção apical mais alargada, formando uma clava. Os artículos antenais (Fig. 29) conferem aspecto ondulado, desprovidos de tubérculos.

A cabeça possui um par de projeções (Figs. 22, 26; Cp) inseridas anteriormente, as quais apresentam-se achatadas dorso-ventralmente. A superfície destas projeções tem aspecto corrugado (Fig. 27), ao contrário do tegumento cefálico, o qual apresenta-se ornamentado por pequenos tubérculos (Fig. 25).

As pernas protorácicas (Fig. 22, Le1) são relativamente mais curtas, cerca de um terço do comprimento das asas. As pernas mesotorácicas (Fig. 22; Le2) estendem-se entre as antenas e as pernas protorácicas. As pernas metatorácicas são quase 
que totalmente cobertas pelas asas anteriores, sendo visível somente sua porção distal.

Em vista dorsal, podem ser notadas cinco linhas de tubérculos: uma linha médio-dorsal, um par de linhas láterodorsal e um par de linhas supraespiracular (Fig. 23). Nota-se em todos os tubérculos o mesmo aspecto corrugado do tegumento observado nas projeções cefálicas (Fig. 27). O par de linhas subespiracular notada por Mosher (1916) em outras espécies de Nymphalidae está ausente em E. isabella.

Os tubérculos médio-dorsais (Fig. 23, Mt) estão presentes somente do segundo ao sexto segmento abdominal. Os tubérculos laterais (Figs. 23, 30; Lt) estão representados desde o primeiro segmentos torácico até o oitavo segmento abdominal, com aspecto variável. Nos segmentos abdominais, com exceção do primeiro, segundo e oitavo, os tubérculos laterais são bífidos (Fig. 34), sendo que no terceiro e no quarto um dos ramos é muito alongado (Fig. 35). No sétimo segmento abdominal a diferença de comprimento entre os ramos também é distinta, embora mais curto que os do terceiro e quarto segmentos. Os tubérculos supraespiraculares (Fig. 23, Se) ocorrem apenas no segundo, terceiro e quarto segmentos.

Lateralmente, existem duas projeções anteriores na base da asa e uma série de três projeções próxima à margem externa da asa anterior, denominadas por BEEBE et al. (1960) tubérculos basilares (Fig. 32, Bt) e submarginais (Figs. 23, 33; St), respectivamente. Os espiráculos são visíveis no tórax e no abdômen. $\mathrm{O}$ espiráculo mesotorácico localiza-se em um sulco na conjunção entre o pro- e mesotórax. No abdômen, os espiráculos estão presentes do primeiro ao oitavo segmento, possuindo forma elíptica alongada. O espiráculo do primeiro segmento é coberto pelas asas e o do oitavo segmento não apresenta abertura distinta, sendo não funcional. Estas observações estão de acordo com o padrão geral descrito para Lepidoptera (MosHer 1916).

A porção terminal do abdômen é curvada ventralmente, como em outras espécies do gênero (Brown 1981). Em $E$. isabella dianasa esta curvatura é pronunciada fazendo com que o oitavo e o nono segmentos estejam justapostos e
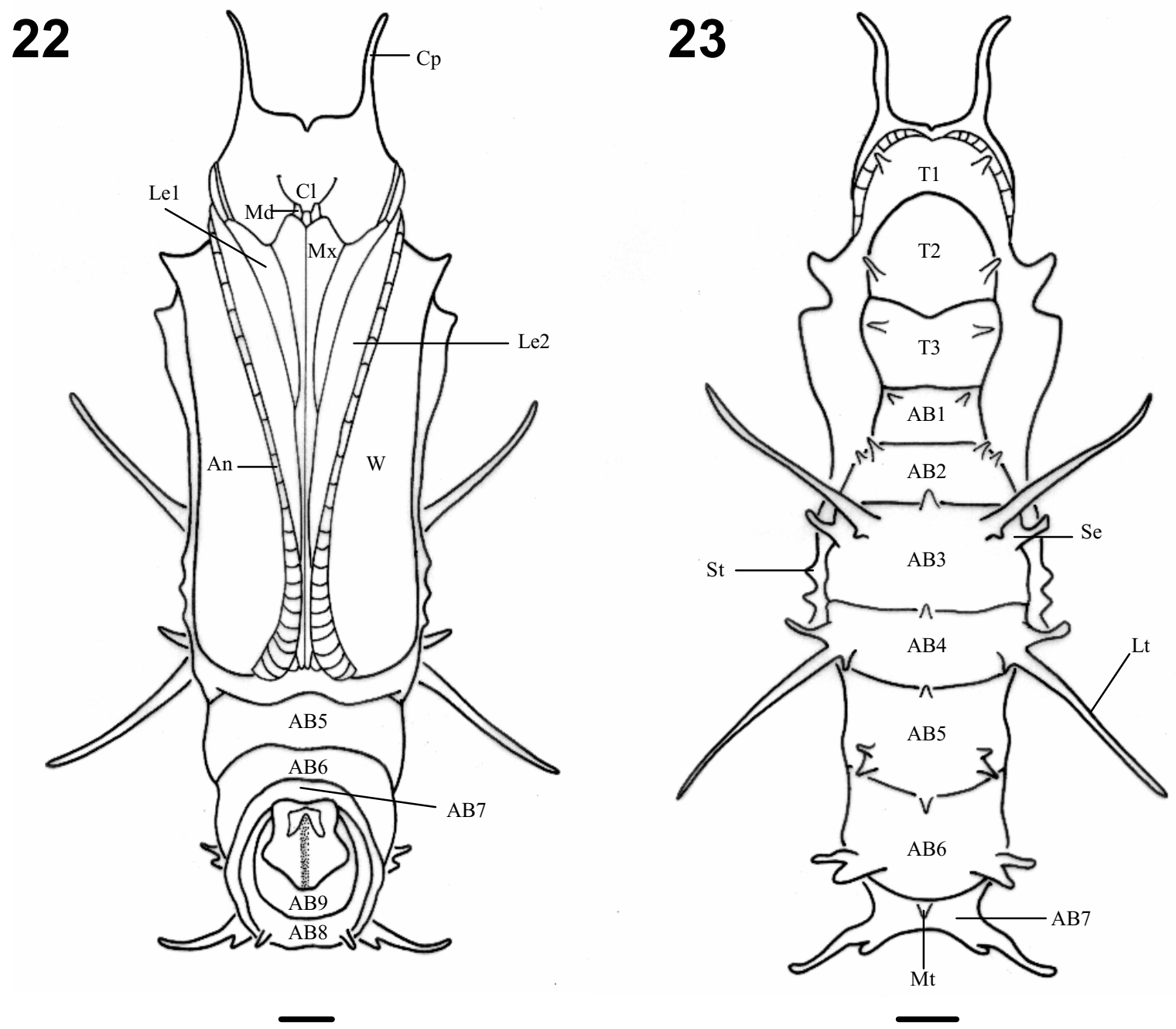

Figs. 22-23. Pupa de E. isabella dianasa. 22, vista ventral; 23, vista dorsal. $A B=$ segmento abdominal; $A n=$ antena; $C p=$ projeção cefálica; Le1= perna protorácica; $\mathrm{Le} 2=$ perna mesotorácica; $\mathrm{Lt}=$ tubérculo lateral; $\mathrm{Md}=$ mandíbula; $\mathrm{Mt}=$ tubérculo médio-dorsal; $\mathrm{Mx}=$ maxila; $\mathrm{Se}=$ tubérculo supraespiracular; $\mathrm{St}=$ tubérculo submarginal; $\mathrm{T}=$ segmento torácico; $\mathrm{W}=$ asa. Barras $=1 \mathrm{~mm}$. 
cobertos pelas papilas anais, o que dificulta a determinação do sexo.

O cremáster (Fig. 36) apresenta-se como uma estrutura triangular em vista ventral, encontrando-se parcialmente sobreposto em relação às papilas anais. Sua região médiolongitudinal apresenta de 120 a 150 ganchos. Estes formam fileiras mais claramente definidas na parte central, em número de 6, aumentando em direção às extremidades. Cada gancho
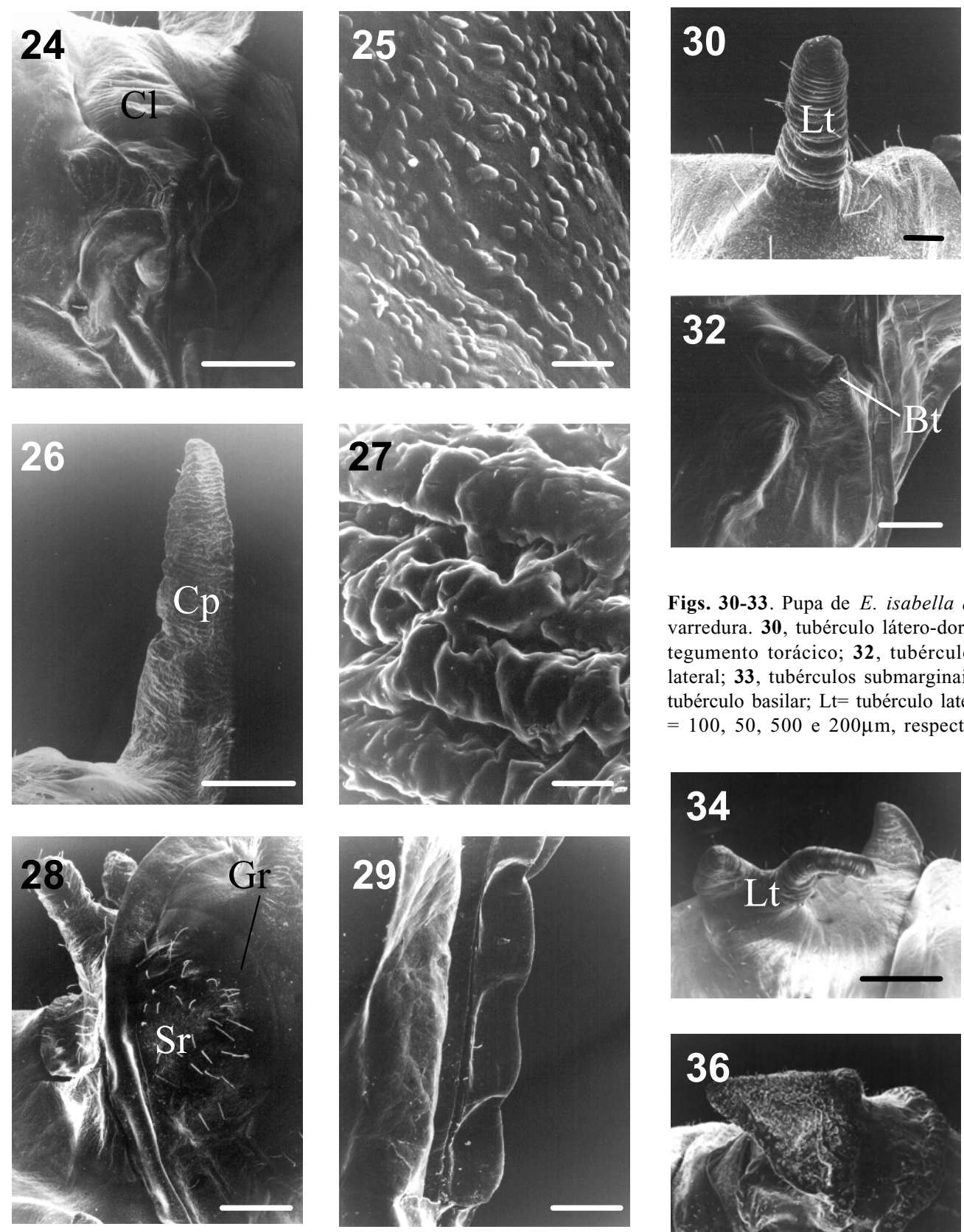

Figs. 24-29. Pupa de E. isabella dianasa em microscopia eletrônica de varredura. 24, vista látero-ventral da cabeça; 25, tegumento cefálico; 26, projeção cefálica em vista lateral; 27 , tegumento da projeção cefálica; 28, olho em vista lateral; 29, porção distal da antena em vista lateral. $\mathrm{Cl}=$ clípeo; $\mathrm{Cp}=$ projeção cefálica; $\mathrm{Gr}=$ faixa de aspecto lustroso do olho; $\mathrm{Sr}=$ porção esculturada do olho. Barras $=500,10,500,10,500$ e $200 \mu \mathrm{m}$, respectivamente.
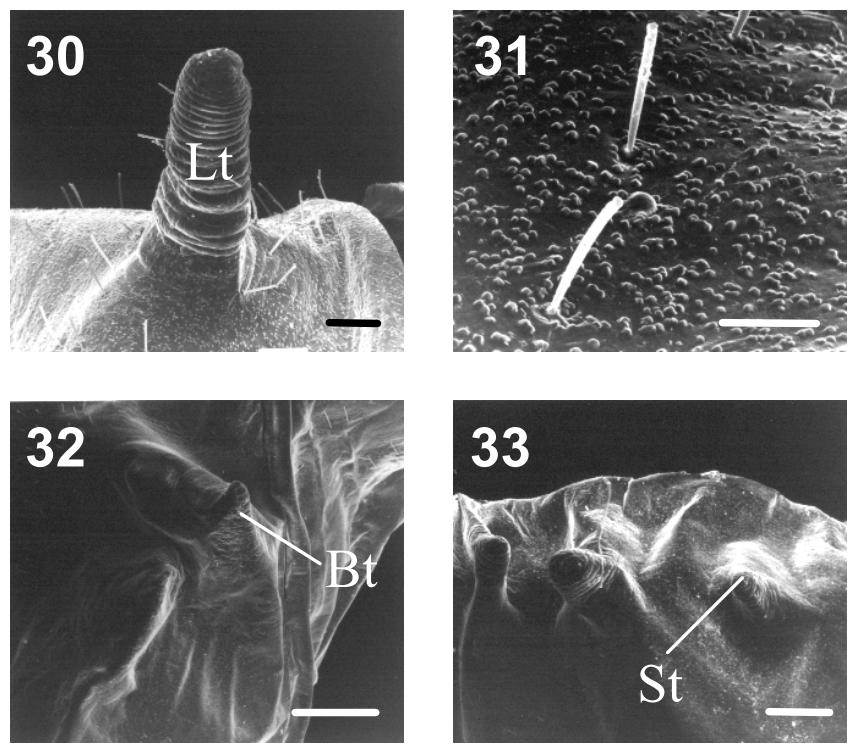

Figs. 30-33. Pupa de E. isabella dianasa em microscopia eletrônica de varredura. 30, tubérculo látero-dorsal metatorácico, em vista lateral; 31, tegumento torácico; 32, tubérculos basilares da asa direita, em vista lateral; 33, tubérculos submarginais da asa direita, em vista lateral. $\mathrm{Bt}=$ tubérculo basilar; $\mathrm{Lt}=$ tubérculo lateral; $\mathrm{St}=$ tubérculo submarginal. Barras $=100,50,500$ e $200 \mu \mathrm{m}$, respectivamente.
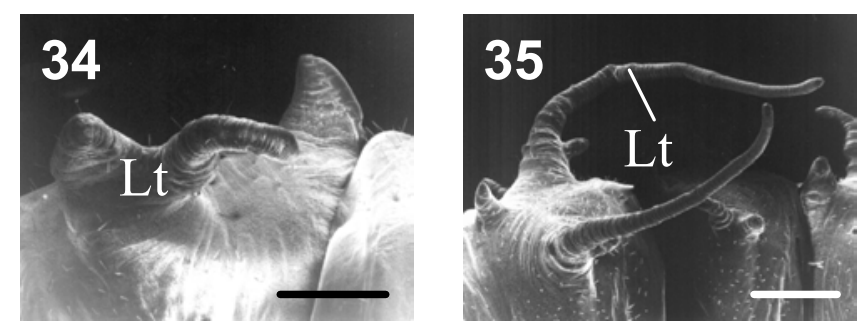

tem a extremidade recurvada e subdividida em duas pontas

No que se refere à coloração da pupa, E. isabella dianasa apresenta variação durante a ontogênese. De uma maneira longitudinalmente (Fig. 21). A coloração de fundo tende ao branco na cabeça e região alar do tórax e cinza-escuro no dorso. No abdômen, tende ao amarelo-esverdeado, sendo que este
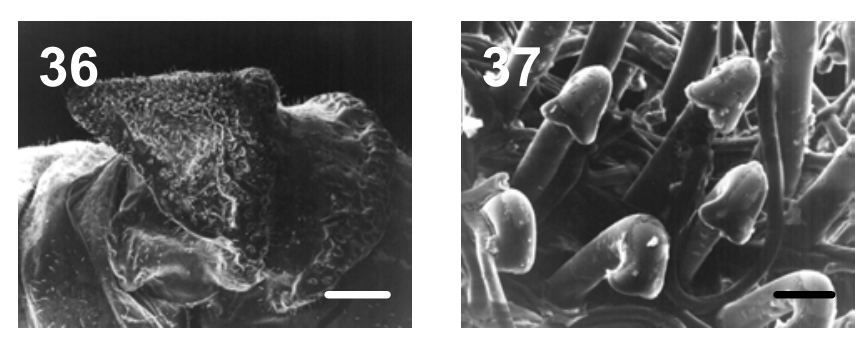

Figs. 34-37. Pupa de E. isabella dianasa em microscopia eletrônica de varredura. 34, tubérculo látero-dorsal do sexto segmento abdominal, em vista lateral; 35, tubérculo látero-dorsal do terceiro segmento abdominal, em vista lateral; 36, cremáster ; 37, detalhe dos ganchos do cremáster. $\mathrm{Lt}=$ tubérculo lateral. Barras $=500,100,500$ e $20 \mu \mathrm{m}$, respectivamente. 
último se pronuncia nas membranas intersegmentares. Observam-se, ainda, regiões avermelhadas na asa e no ventre próximo às projeções cefálicas, bem como uma região enegrecida envolvendo o espiráculo do quarto segmento abdominal e os tubérculos submarginais da asa. Os tubérculos e os espiráculos são amarelos.

Agradecimentos. Os autores agradecem ao Centro de Microscopia Eletrônica da UFRGS, em especial à Christiane Lopes, Francis Farret Darsie e Miriam Souza dos Santos pelo auxílio prestado na preparação das amostras e realização das fotos. Da mesma forma, a Lucas A. Kaminski pela discussão constante no decorrer do trabalho, a Marcelo Duarte (UFPR) quanto às sugestões referentes à uniformização da terminologia utilizada, e a dois revisores anônimos pelas correções e sugestões efetuadas na versão final do manuscrito. Também às direções da FEPAGRO (Estação Experimental de Maquiné) e Herbário Barbosa Rodrigues (Parque Morro Baú, Ilhota) pela permissão quanto às coletas de E. isabella dianasa. Parte dos custos deste estudo foi mantido pela FAPERGS, Projeto n ${ }^{\circ}$ 94/50941.7, concedido a Gilson R.P. Moreira.

\section{REFERÊNCIAS}

Beebe, W.; J. Crane \& H. Fleming. 1960. A comparison of eggs, larvae and pupae in fourteen species of heliconiine butterflies from Trinidad W.I. Zoologica 45: 111-154.

Benson, W.W.; K. S. Brown JR. \& L. E. Gilbert. 1976. Coevolution of plants and herbivorous: passion flowers butterflies. Evolution 29: 659-680.

Biezanko, C. M.; A. Ruffineli \& D. Link. 1978. Catálogo de lepidópteros do Uruguai. Revista do Centro de Ciências Rurais 8: 1-84.

Brower, V. Z. A. 1997. The evolution of ecologically important characters in Heliconius butterflies (Lepidoptera: Nymphalidae): a cladistic review. Zoological Journal of the Linnean Society 119: 457-472.

Brown JR., K. S. 1981. The biology of Heliconius and related genera. Annual Review of Entomology 26: 427-456.

Brown JR., K. S. 1992. Borboletas da Serra do Japí: diversidade, hábitats, recursos alimentares e variação temporal. p. 142-187 In: L.P.C. Morellato (org.) História Natural da Serra do Japí: Ecologia e preservação de uma área florestal no sudeste do Brasil.
Campinas, Unicamp/ Fapesp.

Brown JR, K. S. \& O. H. H. Mielke. 1972. The heliconians of Brazil (Lepidoptera: Nymphalidae). Part II. Introduction and general comments, with a supplementary revision of the tribe. Zoologica 57:1-140.

Chacon, P. \& M. Rojas. 1984. Entomofauna asociada a Passiflora mollisima, P. edulis f. flavicarpa y $P$. quadrangularis en el departamento del Valle del Cauca. Turrialba 34: 297-311.

Daly, H. V. 1985. Insect morphometrics. Annual Review of Entomology 30: 415-438.

Downey, J. C \& A. C. Allyn JR. 1981. Chorionic sculpturing in eggs of Lycaenidae. Part I. Bulletin of the Allyn Museum 61: 1-29.

EmsLey, M. 1963. A morphological study of imagine Heliconiinae (Lepidoptera: Nymphalidae) with a consideration of the evolutionary relationships within the group. Zoologica 48: 85-130.

Fleming, H. 1960. The first instar larvae of the Heliconiinae (Butterflies) of Trinidad, W.I.. Zoologica 45: 91-110.

Gilbert, L. E. 1991. Biodiversity of a Central American Heliconius community: pattern, process, and problems, p. 403-427. In: P.W. Price; T. L. Lewinsohn; G. W. Fernandes \& W.W. Benson (eds.). Plant-animal interactions: evolutionary ecology in tropical and temperate regions. New York, John Willey \& Sons.

Hinton, H. E. 1981. Biology of insect eggs. 3v. London, Pergamon Press, $1125 \mathrm{p}$.

Holzinger, H. \& R. Holzinger. 1994. Heliconius and related genera: Lepidoptera Nymphalidae. The genera Eueides, Neruda and Heliconius. Venette, Sciences Nat., 328 p.

Kaminski, L. A.; M. Tavares; V. G. Ferro \& G. R. P. Moreira. (prelo). Morfologia externa dos estágios imaturos de heliconíneos neotropicais: III. Heliconius erato phyllis (Fabricius, 1775) (Lepidoptera, Nymphalidae, Heliconiinae). Revista Brasileira de Zoologia.

Lee, C. S.; B. A. McCool; J. L. Moore, D. M. Hills \& L. E. Gilbert. 1992. Phylogenetic study of heliconiine butterflies based on morphology and restriction analysys of ribosomal RNA genes. Zoological Journal of the Linnean Society 106: 17-31.

Miller, J. S. \& L. D. Otero. 1994. Immature stages of venezuelan Dioptinae (Notodontidae) in Josia and Thirmida. Journal of the Lepidopterists' Society 48: 338-372.

Mosher, E. 1916. A classification of the Lepidoptera based on characters of the pupa. Bulletin of the Illinois State Laboratory of Natural History 12: 1-165

Otero, L. S. 1986. Borboletas: O livro do naturalista. Rio de Janeiro, FAE, 112 p.

Stehr, F. W. 1987. Order Lepidoptera. p. 288-596. In: F. W. Stehr (ed.) Immature insects. Dubuque, Kendall/Hunt. 